\title{
Euthyroid goitre and sleep apnea
}

\author{
A. De Felice, S. Fuschillo, M. Martucci, E. De Angelis, G. Balzano
}

ABSTRACT: Euthyroid goitre and sleep apnea. A. De Felice, S. Fuschillo, M. Martucci, E. De Angelis, G. Balzano. A number of predisposing factors (obesity, nasal obstruction, adenoidal hypertrophy, macroglossia, etc) have been related to obstructive sleep apnea syndrome (OSAS). In addition hypothyroidism and large goitres have been reported to be associated to OSAS, but this association has not been adequately studied.

We describe an obese patient with euthyroid goitre associated with OSAS. The patient showed a body mass index (BMI) of 47 and a large neck with a circumference of $60 \mathrm{~cm}$. The flow-volume curve demonstrated an expiratory plateau suggesting an intrathoracic upper airway obstruction. Arterial blood gas analysis results were: $\mathrm{pH}$ 7.39; $\mathrm{PCO}_{2} \mathbf{5 4 . 2}$ mmHg; $\mathrm{P} \mathrm{O}_{2} 47 \mathrm{mmHg}$. Nocturnal polisomnography showed an apnea/hypopnea index (AHI) of 31 episodes/hour. Upper airway collapse was overcome by a nasal continuous positive airway pressure (nCPAP) of $14 \mathrm{cmH}_{2} \mathrm{O}$.

Weight loss obtained by a hypocaloric diet was not accompanied by any OSAS improvement. After thyroidectomy, a nCPAP of $4 \mathbf{c m H}_{2} \mathrm{O}$ was sufficient to prevent upper airway closure.

Discontinuation of nCPAP treatment for 4 consecutive nights did not determine worsening of sleep apnea symptoms, nor a worsening of overnight oxymetry. A new polysomnography carried out after 4 nights off nCPAP showed an AHI of 33 episodes/hour.

OSAS should be suspected in patients with large goitres. Decisions regarding discontinuation of nCPAP treatment after thyroidectomy should be based on polisomnographic results.

Monaldi Arch Chest Dis 2006; 65: 1, 52-55.

Keywords: Goitre, sleep apnea, continuous positive airway pressure.

Division of Pneumology, Salvatore Maugeri Foundation, Scientific Institute of Telese Terme (BN), Italy.

Correspondence: Giovanni Balzano, MD, Division of Pneumology, Scientific Institute of Telese Terme (BN), Salvatore Maugeri Foundation, Via Bagni Vecchi 1, Telese Terme (BN), 82037 Italy; e-mail: gbalzano@fsm.it

\section{Introduction}

Obstructive sleep apnea syndrome (OSAS) is characterised by repetitive episodes of complete (apnea) or partial (hypopnea) occlusion of the upper airways during sleep, generally associated with oxyhaemoglobin desaturation and sleep fragmentation [1]. The clinical consequences of OSAS may include snoring, exessive daytime sleepiness [2], sistemic hypertension [3], pulmonary hypertension [4], cardiac arrhytmias [5], ischaemic heart disease [6], and strokes [7].

The development of OSAS has been related to a variety of predisposing factors, such as obesity [8], nasal obstruction [9], adenoidal and/or tonsillar hypertrophy [10], macroglossia [11], retrognathia, micrognathia [12], acromegaly [13], and hypothyroidism [14]. Moreover, it has been reported that a large goitre, independent from the co-existence of hypothyroidism, may per se concur to the development of OSAS, and that, in these cases OSAS may improve with thyroidectomy $[15,16$, 17]. The pathogenetic relationship between a large euthyroid goitre and the upper airway obstruction in OSAS is, at the moment, speculative, and may recognize several mechanisms. These include a lower venous return from the head and neck, with oedema and reduced patency of the upper airways [15], a tracheal displacement interfering with the upper airway stiffening reflex during inspiration [18], a mass loading effect on the airways [19], and, finally, a reduced activity of the pharingeal dilator muscles [20].

Here we report a case of a patient with an euthyroid goitre associated with OSAS, that improved after thyroidectomy.

\section{Case report}

In October 1998, a 67 year old man was referred to our sleep laboratory for suspected OSAS. He complained about gasping during sleep, heavy snoring every night, daytime somnolence, and exertional dyspnea.

Clinical examination showed an obesity III degree, with a body mass index (BMI; $\mathrm{Kg} / \mathrm{m}^{2}$ ) of 47 , and a large neck, with a circumference of $60 \mathrm{~cm}$, and a percent predicted neck circumference of $150 \%$ (PPNC). Chest auscultation did not reveal pathologic sounds, and arterial blood pressure was normal. A questionnaire for somnolence revealed an Epworth score of 13 [21].

Forced expiratory volume in one second $\left(\mathrm{FEV}_{1}\right)$ was $91 \%$ of predicted value, and forced vital capacity (FVC) $101 \%$ of the predicted value, with an $\mathrm{FEV}_{1} / \mathrm{FVC}$ ratio of $71 \%$. The shape of the flow-volume curve showed an expiratory plateau, with a peak expiratory flow rate (PEFR) of 52\% of predicted, suggesting an intrathoracic upper airway obstruction (fig. 1, panel A). Arterial blood gas analysis while breathing ambient air was as follows: $\mathrm{pH}$ 7.39; $\mathrm{PaCO}_{2} 54.2 \mathrm{mmHg} ; \mathrm{PaO}_{2} 47 \mathrm{mmHg}$. 


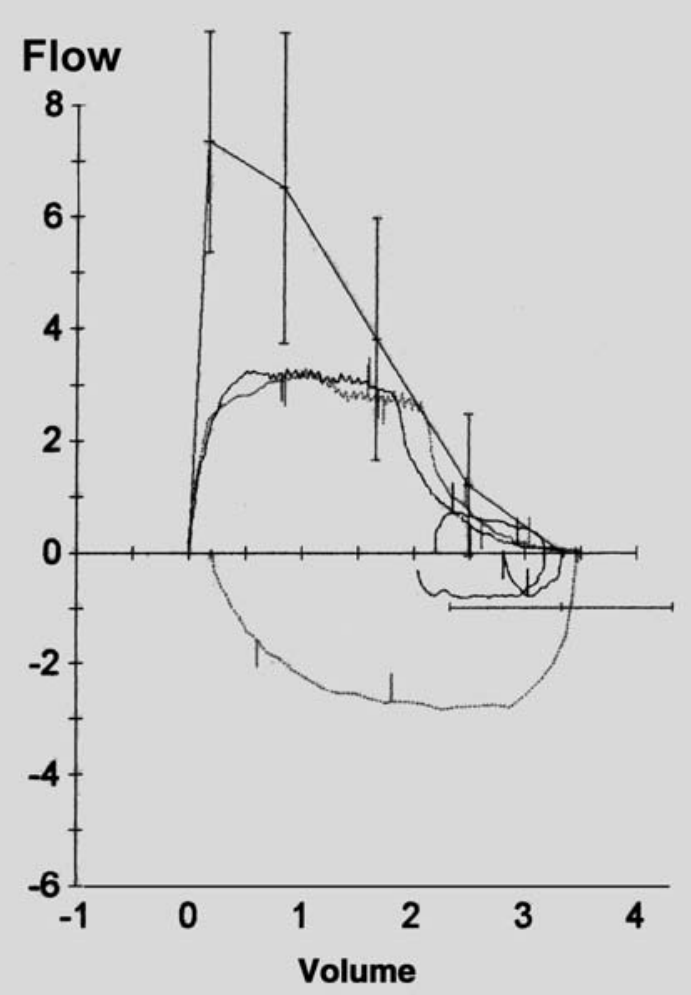

Panel A

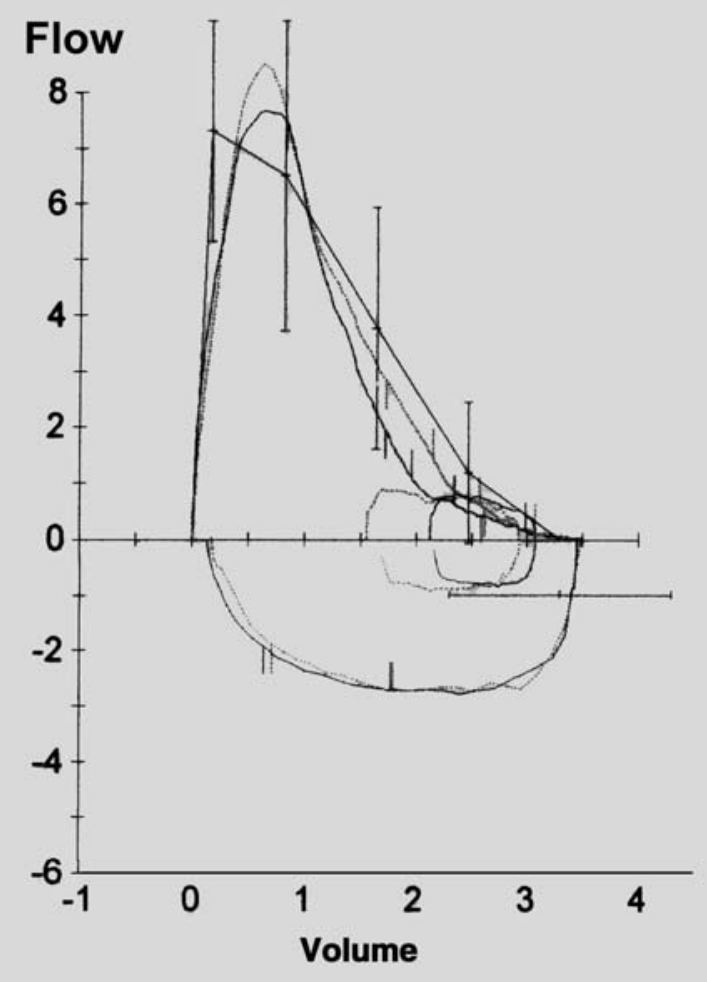

Panel B

Fig. 1. - Flow-volume loopes before (panel A) and after (panel B) thyroidectomy.

A computerised tomography (CT) scan of the neck showed an enlargement of the thyroid gland, the longitudinal diameter of the right and left lobe being 11 and $6.4 \mathrm{~cm}$, respectively (normal size being 4-6 cm), with a compression and displacement to the left of the trachea; the right thyroid lobe extended retrosternally down to the mediastinal region. Both the pharyngoscopy and indirect laryngoscopy were normal.

Serum thyroid hormones were in the normal range (FT3 $3.28 \mathrm{pg} / \mathrm{ml}$, normal range 2.6-5.1; FT4 $0.93 \mathrm{ng} / \mathrm{dl}$, normal range $0.9-1.9$; TSH $0.65 \mu \mathrm{U} / \mathrm{ml}$, normal range 0.23-4).

A nocturnal polisomnographic evaluation, including monitoring of oronasal air flow, chest and abdominal movements, body position, electroencephalogram, electrooculogram, electrocardiogram, and pulse oximetry, documented a total of $818 \mathrm{dips}$ (92.8 dips/hour), the lowest value of $\mathrm{Sa}$ $\mathrm{O}_{2}$ recorded being $47 \%$, the percent of time spent below an $\mathrm{Sa} \mathrm{O}_{2}$ value of $90 \%$ being $97 \%$, the mean saturation value being $74 \%$ and the apnea/hypopnea index (AHI; episodes/hour) being 31, indicating the presence of OSAS.

Thus, an overnight nasal continuous positive airway pressure (nCPAP) ventilation treatment was instituted, by means of an auto-titrating device (Virtuoso; Repironics, Murrysville, USA). The pressure required to prevent upper airway closure resulted to be $14 \mathrm{cmH}_{2} \mathrm{O}$.

As expected, after two weeks of nCPAP treatment, daytime arterial blood gas analysis while breathing ambient air improved dramatically, show- ing a pH of 7.42, a $\mathrm{PaCO}_{2}$ of $40 \mathrm{mmHg}$, and a $\mathrm{PaO}_{2}$ of $60 \mathrm{mmHg}$. The patient was then discharged.

After 6 months of continuous domiciliary nCPAP treatment, the patient reported remission of symptoms, and the Epworth score for sleepiness was 4. Compliance with treatment was good, with an utilisation time of 5 hour/night. Arterial blood gas analysis improved further and showed the following values: $\mathrm{pH} 7.45, \mathrm{PaCO}_{2} 40 \mathrm{mmHg}$, and $\mathrm{PaO}_{2} 75.2 \mathrm{mmHg}$. A relevant weight loss was also found, with a BMI of 37 and a PPNC of 125 .

An overnight oximetry during nCPAP ventilation documented a total of $10 \mathrm{dips}$ (1.7 dips/hour) of $>4 \%$ in arterial oxygen saturation $\left(\mathrm{Sa} \mathrm{O}_{2}\right)$, the lowest value of $\mathrm{Sa} \mathrm{O}_{2}$ recorded being $89 \%$, and the percent of time spent below an $\mathrm{SaO}_{2}$ value of $90 \%$ being close to zero.

Given the relevant weight loss, the patient underwent a new nCPAP titration with auto-CPAP, and this confirmed an airway pressure of 14 $\mathrm{cmH}_{2} \mathrm{O}$ to overcome the upper airway collapse.

In September 1999, the patient underwent total thyroidectomy through collar incision. Hystological examination of the gland, weighing $370 \mathrm{~g}$, demonstrated a multinodular structure, with several colloidal and hemorrhagic areas. A hormonal replacement therapy was institued with L-thyroxine, and the patient was made euthyroid.

In November 1999, the patient complained about difficulties in utilising nCPAP, so he was readmitted to our clinic.

The shape of the flow-volume curve was normal, with the resolution of the expiratory plateau 
Table 1. - Nocturnal oxymetric values obtained over four consecutive nights after the discontinuation of nCPAP treatment

\begin{tabular}{ccccc}
\hline Off nCPAP & Dips $\mathrm{Sa} \mathrm{O}_{2}>4 \%$ & Dips/hour & T 90\% & ${\text { Nadir Sa } \mathrm{O}_{2}}^{2}$ \\
\hline First night & 21 & 3 & 2 & $86 \%$ \\
Second night & 27 & 3.6 & 4 & $85 \%$ \\
Third night & 31 & 4.1 & 3 & $82 \%$ \\
Fourth night & 15 & 2.5 & 2 & $85 \%$ \\
\hline
\end{tabular}

and reappearance of a normal PEFR (fig. 1, panel B). The arterial blood gas analysis was in the normal range. A CT scan of the neck documented resolution of the alterations previously described.

A new nCPAP titration with auto-CPAP revealed a pressure of $4 \mathrm{cmH}_{2} \mathrm{O}$ to prevent the upper airway closure. An overnight oximetry during a nCPAP ventilation of $4 \mathrm{cmH}_{2} \mathrm{O}$ documented a total of 8 dips ( $1 \mathrm{dip} /$ hour) of $>4 \%$ in arterial oxygen saturation $\left(\mathrm{Sa} \mathrm{O}_{2}\right)$, the lowest value of $\mathrm{Sa} \mathrm{O}_{2}$ recorded being $86 \%$, and the percent of time spent below $90 \%$ being zero.

Thus, the nCPAP treatment was discontinued, and an overnight oxymetry was performed for 4 consecutive nights (tab. 1).

A new polisomnography, carried out after 4 nights off nCPAP, showed an AHI of 33 episodes per hour. Thus, the patient was discharged, with a prescription for a nocturnal nCPAP ventilation set at a pressure of $4 \mathrm{cmH}_{2} \mathrm{O}$, as established on the last titration.

\section{Discussion}

The case reported here confirms and extends the little data available in the literature, regarding the relationship between goitre and OSAS.

An earlier report by Stafford and collegues described an acromegalic patient with retrosternal goitre, OSAS, and respiratory failure, whose sleep apnea symptoms improved after thyroidectomy [15]. In a series of 280 patients with OSAS, Langevin found two cases of euthyroid goitre [16]. Finally, in a study similar to the present, Deegan reported two euthyroid patients with a large goitre, in whom the diagnosis of OSAS was made on a clinical basis [17]; in both patients the sleep apnea symptoms improved following partial thyroidectomy, so that it was possible to discontinue the $\mathrm{nC}$ PAP treatment, whithout reappearance of daytime somnolence [17].

In the case reported here, the patient experienced a significant improvement in both sleep apnea symptoms and arterial blood gas analysis following treatment with nCPAP. The treatment was well tolerated, and compliance was good. However, after thyroidectomy, the previously employed continous positive airway pressure of $14 \mathrm{cmH}_{2} \mathrm{O}$ was no longer tolerated, and the patient compliance to the treatment diminished; so a new nCPAP titration was made, and the pressure reduced to 4 $\mathrm{cmH}_{2} \mathrm{O}$. This was well tolerated, and compliance increased again.
The reduced positive airway pressure needed could have been due to both weight loss and thyroidectomy. In fact, weight loss has been shown in several studies to reduce the severity of OSAS, by decreasing the collapsability of the upper airways [21-23]. However, in our patient, this was probably not the case, because nCPAP titration had resulted in an unchanged positive airway pressure need after weight loss, whereas a consistent reduction in pressure was possible only after thyroidectomy.

An interesting finding of this study was that, after thyroidectomy and four nights of discontinuation of nCPAP, an overnight oximetry documented an ODI of $2.5 / \mathrm{h}$, that is of no clinical significance; the patient, despite the nCPAP discontinuation, did not complain about a worsening of sleep apnea symptoms. However, at the same time point, an objective polisomnographic assessment demonstrated an AHI of 33, not substantially different from the initial value of 31 , but apparently in contrast with the corresponding value of ODI.

The present case report confirms the possible association between goitre and OSAS, and suggest that diagnostic tests for OSAS should be included in the evaluation of patients with large goitres.

The findings of the present study have important clinical implications. In patients with goitre and OSAS, decisions about discontinuation of nCPAP treatment after thyroidectomy should not be based on clinical symptoms or overnight oximetry only, but on objective evaluations, namely polysomnographic studies.

\section{References}

1. Remmers JE, DeGroot WJ, Sauerland EK, Anch AM. Pathogenesis of upper airway occlusion during sleep. $J$ Apll Physiol 1978; 44: 931-38.

2. American Sleep Disorders Association: The International Classification of sleep disorders: Rochester, Minn, 1990.

3. Lavie P, Ben-Yosef R, Rubin AE. Prevalence of sleep apnea syndrome among patients with essential hypertension. Am Heart J 1984; 108: 373-76.

4. Tilkian AG, Guilleminault C, Schroeder JS, Lehrman KL, Simmons FB, Dement WC. Hemodynamics in sleep-induced apnea: studies during wakefulness and sleep. Ann Intern Med 1976; 85: 714-719.

5. Guilleminault C, Connolly SJ, Winkle RA. Cardiac arrhytmia and conduction disturbances during sleep in 400 patients with sleep apnea. Am J Cardiol 1983; 52: 490-494.

6. Hung J, Whitford EG, Parson RE, Hillman DR. Association of sleep apnoea with myocardial infarction in men. Lancet 1990; 336: 261-4. 
7. Spriggs DA, French JM, Murdy, Curless RH, Bates D, James OFW. Snoring increases the risk of stroke and adversely affects prognosis. $Q$ J Med 1992; 303: 555-62.

8. Vgontzas A, Tan T, Bxler E, Martin L, Shubert D, Kales A. Sleep apnea and sleep apnea disruption in obese patients. Arch Intern Med 1994; 154: 1705-11.

9. Olsen KD, Kern EB, West Brook PR. Sleep and breathing disturbance secondary to nasal obstruction. Otolaryngol Head Neck Surg 1981; 89: 804-10.

10. Mangat D, Orr WL, Smith RO. Sleep apnea, hypersomnolence, and upper airway obstruction secondary to adenotonsillar enlargement. Arch Otolaryngol 1977; 103: 383-6.

11. Lowe AA, Gionhaku N, Takeuchi K, Fleetham JA. Three-dimensional CT reconstructions of tongue and airway in adult subjects with obstructive sleep apnea. Am J Orthod Dentofacial Orthop 1986; 90: 364-74.

12. Lyberg T, Krogstad O, Djupesland G. Cephalometric analysis in patients with obstructive sleep apnoea syndrome. I. Skeletal morphology. J Laryngol Otol 1989; 103: 287-92.

13. Mickelson SA, Rosenthal LD, Rock JP, Senior BA, Friduss ME. Obstructive sleep apnea syndrome and acromegaly. Otolaryngol Head Neck Surg 1994; 111: 25-30.
14. Lin C, Tsan K, Chen P. The relationship between sleep apnea syndrome and hypotiroidism. Chest 1992; 102: 1663-7

15. Stafford N, Youngs R, Waldron J, Baer S, Randall C. Obstructive sleep apnea in association with retrosternally goitre and acromegaly. J Laryngol Otol 1986; 100: 861-63.

16. Langevin B, Sukkar F, Léger P, Guez A, Robert D. Sleep apnea syndrome (SAS) of specific etiology: Review and incidence from a sleep laboratory. Sleep 1992; 15: S25-S32.

17. Deegan PC, McNamara VM, Morgan WE. Goitre: a cause of obstructive sleep apnea in euthyroid patients. Eur Respir J 1997; 10: 500-2.

18. Van de Graaff WB. Thoracic influence on upper airway patency. J Appl Physiol 1988; 65: 2124-2131.

19. Strobel RJ, Rosen RC. Obesity and weigth loss in obstructive sleep apnea: a critical review. Sleep 1996; 19: 104-15.

20. Van Lunteren E, Haxhin MA, Cherniack NS. Relation between upper airway volume and hyoid muscle length. J Appl Physiol 1987; 63: 144-49.

21. Johns MW. A new method for measuring daytime sleepiness: The Epworth Sleepiness Scale. Sleep 1991; 14: 540-545.

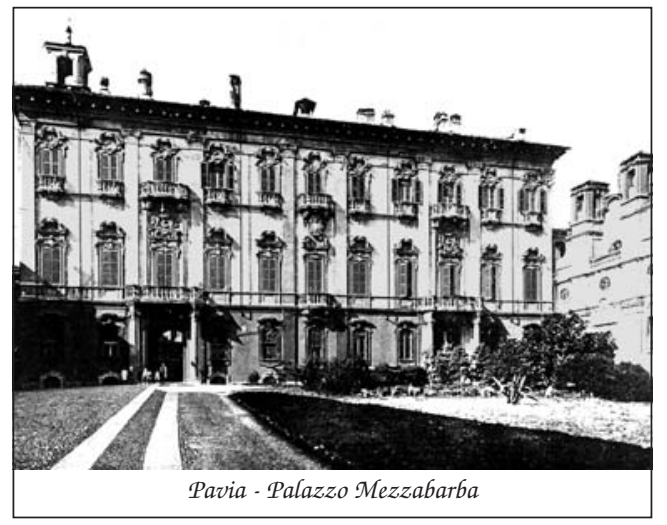

